\title{
Autonomic Nervous System Part
}

National Cancer Institute

\section{Source}

National Cancer Institute. Autonomic Nervous System Part. NCI Thesaurus. Code C34060.

Any component of the sympathetic or parasympathetic nervous system. 